\title{
PERAN YPKP SEBAGAI KELOMPOK KEPENTINGAN (INTEREST GROUP) DALAM MEMERJUANGKAN HAK HAK KORBAN PERISTIWA G30S (Studi Kasus Aktivitas YPKP di Kabupaten Pati)
}

\author{
Adipta Wisnu Wardhani
}

\begin{abstract}
Indonesia is one of the countries that embraced democracy in system administration. Indonesia has proved it by holding presidential and vice presidential election directly. Besides the Indonesian people freely organizing meetings and talking freely to express opinions, criticism, or even overseeing the governance system. Freedom of religion is a manifestation of the democratic state.

The dynamics of the Non-Governmental Organization (NGO) was born along with the birth of a new order of the early 1970s. The birth of this order to the economic development paradigm and focusing on economic growth, had an impact on short-term plans, medium and long-national development, which is implemented in the five year plan. $N G O$ as a partner of government to accelerate the process of national development in all fields.

This research will be directed to find out how YPKP activity as well as how the interaction / relationship dynamics YPKP with the Government. Murder Victims Research Foundation 1965/1966 (YPKP 65) is the organization's first victim in Indonesia fighting for the enforcement of human rights on Human Tragedy 1965/1966. YPKP 65 judging cases of crimes against humanity 1965/1966 has not been seriously considered in law and politics of the country. During the 12 years of reform, none of the political elite, both in Parliament and in the executive, even in the judiciary investigate cases in 1965.

After analysis, it appears that YPKP 65 Pati Regency consolidate internally and externally by holding regular meetings so that the communication that exists among members of intertwined smoothly, as did the communications against similar organizations lainnya.YPKP 65 Pati regency using communication media / communication channels that are electronically for obtain information related to the organization's objectives. There was also the dynamics between YPKP with another NGO.
\end{abstract}

Keywords: Role, Interest Groups, Dynamics.

\section{A. PENDAHULUAN}

Negara Indonesia adalah salah satu negara yang menganut demokrasi dalam sisitem pemerintahannya. Indonesia sudah membuktikan hal tersebut dengan mengadakan pemilihan presiden dan wakil presiden secara langsung. Selain itu masyarakat Indonesia bebas menyelenggarakan pertemuan dan bebas berbicara untuk mengeluarkan pendapat, kritikan, atau bahkan mengawasi jalannya sistem pemerintahan. Kebebasan dalam memeluk agama pun merupakan sebuah perwujudan dari negara demokratis. Dalam membangun sebuah negara demokratis tidaklah mudah. Akan tetapi, di negara ini, sistem demokrasi terlaksana dengan adanya kebebasan berkeyakinan, berpendapat, atau kebebasan untuk berkumpul tanpa ada batasan. Maka dari itu muncullah kelompok kepentingan, mengandung arti sejumlah orang yang 
memiliki kesamaan sifat, sikap, kepercayaan, dan tujuan sepakat mengorganisasikan diri untuk melindungi dan mencapai tujuan (Ramlan Surbakti,1992:55).

Berbicara mengenai demokrasi, Indonesia sudah lama menganut sistem pemerintahan demokratis dimana menganut paham dari rakyat oleh rakyat dan untuk rakyat. Di Indonesia dikenal freedom of association, dimana masyarakat bebas mendirikan organisasi atau perkumpulan dalam rangka memerjuangkan aspirasi mereka. UU No 14 Tahun 2008 mengenai Keterbukaan Informasi Publik pun kini makin memperkuat demokrasi di Indonesia

Dalam sistem demokrasi, baik dalam sistem demokrasi langsung maupun demokrasi perwakilan, adanya kebebasan tertentu bagi rakyat merupakan persyaratan mutlak bagi berlangsungnya sistem, karena hanya dengan kebebasan, rakyat merupakan pemegang kekuasaan tertinggi, terutama dalam sistem demokrasi perwakilan, akan dapat dengan bebas menentukan pilihannya mengenai siapa yang akan didudukkan dalam jabatan publik. Agar seluruh rakyat dapat menentukan pilihannya dengan cerdas, dapat mencalonkan diri di dalam pemilihan pejabat publik, dan dapat terlibat dalam berbagai kegiatan dalam rangka ikut menentukan jalannya pemerintahan negara, maka demokrasi mensyaratkan adanya kebebasan memperoleh dan menyebarkan informasi, bebas untuk berserikat, seperti mendirikan partai politik yang dapat digunakan untuk ikut ambil bagian didalam usaha menduduki jabatan publik melalui pemilihan, atau mendirikan kelompok-kelompok kepentingan dalam rangka mengupayakan diperhatikan, dilindungi, dan direalisasikannya kepentingankepentingan anggota, karena pentingnya kebebasan didalam menentukan berlangsungnya sistem demokrasi, oleh para ahli ketatanegaraan pendukung demokrasi, kebebasan disebut sebagai pilar demokrasi.

Dinamika perkembangan Lembaga Swadaya Masyarakat (LSM) lahir seiring dengan lahirnya orde baru awal tahun 1970-an. Lahirnya orde ini dengan paradigma pembangunan ekonomi serta memfokuskan pada pertumbuhan ekonomi, membawa dampak terhadap rencana jangka pendek, menengah dan panjang pembangunan nasional yang diimplementasikan pada repelita. LSM sebagai salah satu partner pemerintah untuk mempercepat proses pembangunan Nasional dalam segala bidang.

Demokrasi sangat penting kaitannya terhadap pembagian kekuasaan dalam suatu negara, dengan kekuasaan negara yang diperoleh dari rakyat juga harus digunakan untuk kesejahteraan dan kemakmuran rakyat.

Dinamika perkembangan Lembaga Swadaya Masyarakat lahir seiring dengan lahirnya orde baru awal tahun 1970-an. Lahirnya orde ini dengan paradigma pembangunan ekonomi sebagai mainstraimenya serta memfokuskan pada pertumbuhan ekonomi, membawa dampak pada rencana jangka pendek, menengah dan panjang pembangunan Nasional yang diimplementasikan pada repelita. LSM sebagai salah satu partner pemerintah untuk mempercepat proses pembangunan Nasional dalam segala bidang.

Pertumbuhan dan peran LSM di Indonesia semakin berkembang seiring dengan menguatnya proses demokratisasi yang ditandai penguatan masyarakat sipil atau civil society dalam transformasi pembangunan. Selama lima tahun terakhir lebih dari 10.000 LSM bergerak di bidang budaya, sosial ekonomi, politik. Peran strategis LSM ini dalam dasawarsa terakhir menghadapi hambatan ketika LSM ingin mengimplementasikan perannya dalam proses demokratisasi agar dapat memberikan kontribusi pada transformasi politik.

Dalam perkembangannya sering terjadi benturan kepentingan / conflic of interest antara pemerintah dengan masyarakat. Dimana pelaksanaan pembangunan pemerintah 
tidak bisa menyerap $100 \%$ aspirasi masyarakat. Hal ini menyebabkan munculnya tuntutan-tuntutan dari masyarakat yang tidak puas terhadap kebijakan pemerintah. Disinilah LSM menjembatani kepentingan masyarakat tersebut dengan melakukan kritik kepada pemerintah melalui saluran-saluran baik formal maupun non formal.

Satu Kelompok Organisasi YPKP (Yayasan Penelitian Korban Pembunuhan) sebagai bentuk Lembaga Swadaya Masyarakat. Peristiwa G30S Tahun 1965 - 1966 mewadahi orang-orang yang diduga terlibat dalam peristiwa G30S 1965/1966 tersebut.

YPKP (Yayasan Penelitian Korban Pembunuhan) 1965/1966 merupakan kelompok kepentingan (interest groups) yang memerjuangkan nasib korban tidak bersalah namun mendapatkan perlakuan tidak layak. Menjadi menarik bahwa semua anggota YPKP merupakan orang-orang yang mengalami langsung dampak dari dikaitkaitkannya mereka sebagai anggota PKI sehingga mereka ikut di penjara dan meninggalkan keluarga mereka tanpa ada proses hukum yang jelas pada saat itu.

Provinsi Jawa Tengah khususnya di Kabupaten Pati, telah muncul Kelompok Organisasi YPKP ( Yayasan Penelitian Korban Pembunuhan ) Peristiwa G30STahun 1965 - 1966 berfungsi mewadahi orang-orang yang diduga terlibat dalam peristiwa G30S/1966.

Yayasan Penelitian Korban Pembunuhan 1965/1966 (YPKP 65) sebagai organisasi korban pertama di Indonesia berjuang untuk penegakkan hak asasi manusia (HAM) atas Tragedi Kemanusiaan 1965/1966. YPKP 65 menilai kasus kejahatan kemanusiaan 1965/1966 masih belum mendapatkan perhatian serius secara hukum dan politik dari negara. Selama 12 tahun masa reformasi, tidak ada satu pun elit politik, baik di parlemen dan di eksekutif, bahkan di lembaga yudikatif mengusut tuntas kasus 1965.

Guna mengetahui sejauhmana peran kelompok kepentingan ini maka perlu dilaksanakan penelitian mengenai kegiatan yang dilaksanakan oleh YPKP.

\section{B. PEMBAHASAN}

\section{Aktivitas YPKP}

YPKP 65 Pusat adalah singkatan dari Yayasan Penelitian Korban Pembunuhan 65. Atau didalam bahasa inggris : Indonesian Institute For The Study of 65 Massacre. Yayasan ini pertama kali berdiri dengan Ketua Ibu Sulami, bekas Pengurus Pusat Gerwani Jakarta. Didirikan dengan Akte Notaris No. 1/7 April 1999 ditanda tangani oleh Notaris Ny. Nany Wahyudi, SH. dengan alamat: Jln.Pajajaran No. 87 Perumnas III Tangerang - Indonesia. YPKP 65 mempunyai visi dan misi seperti terkandung dalam Pasal 4 AD/ART beserta Penjelasannya, yaitu ikut mencerdaskan bangsa guna mewujudkan masyarakat Pancasila seutuhnya dalam Negara Kesatuan Republik Indonesia, serta menurut makna yang terkandung dalam Pembukaan UUD 1945 berikut ketentuan dalam batang tubuh dan penjelasannya.

Kegiatan yang dilakukan oleh YPKP Kab. Pati merupakan sebuah upaya untuk memerjuangkan hak-hak dimana mereka menuntut pada pemerintah terkait keadilan untuk para korban peristiwa G30S. Kegiatan yang dilakukan oleh YPKP Kab Pati masih bersifat persuasif, dan hanya melakukan aktivitas-aktivitas setiap malam rabu kliwon arisan bersama dan berdiskusi tanpa melakukan melakukan hal hal yang bersifat anarkis. Namun setiap kegiatan mereka masih sangat memerlukan pantauan dari aparat penegak hukum yaitu kepolisian juga TNI. Karena para korban ini memiliki sangkut 
paut dengan partai komunis indonesia yang di khawatirkan akan bangkit kembali dan organisasi ini pun termasuk kedalam organisasi terlarang.

\section{Interaksi}

Hasil penelitian lapangan bahwa YPKP Kab. Pati termasuk organisasi yang paling aktif memerjuangkan para korban G30S. Salah satu indikatornya yaitu Pati menjadi tempat yang dikunjungi mantan menteri hukum dan ham Luhut binsar banjaitan dari sekian banyak yang diduga terdapat kuburan masal. Hal ini karena YPKP Kab. Pati sangat aktif dan vocal dalam setiap kegiatan YPKP di pusat.Sesuai dengan tugas dan wewenang YPKP yaitu :

(1) Mendata Jumlah korban baik yang masih hidup maupun Meninggal dunia;

(2) Mendata Korban yang berada di Pengangsingan Pulau Nusakambangan dan Pulau Buru ( Ambon ) yang sudah pulang / hidup dan Meninggal Dunia di lokasi pengangsingan;

(3) Mendatakan lokasi-lokasi yang diduga sebagai tempat kuburan masal korbankorban peristiwa 1965 di wilayah Kab. Pati;

(4) Mengupayakan perjuangan rehabilitasi nama baik korban peristiwa . 1965/1966, dan mengupayakan bantuan terhadap korban salah satunya melalui pengobatan gratis oleh LPSK ( Lembaga Perlindungan Saksi Korban ) dari Jakarta.

Selama ini kegiatan yang dilaksanakan YPKP Kab. Pati normatif tidak ada indikasi apapun untuk menjurus kepada gerakan anti pancasila. Sebagai perorarangan ketua YPKP Sdr. Handoyo mampu membaur dengan masyarakat bahkan menjadi kepala desa Jetak.

Salah satu kegiatan yang telah dilaksanakan oleh YPKP berupa Bansos dari LPSK Jakarta disertai pemeriksaan kesehatan dan assesment kepada anggota yang diajukan terlebih dahulu. Setiap akan diadakannya kegiatan oleh YPKP selalu memberikan pemberitahun terlebih dahulu kepada Kades waktu dan tempat pelaksanaannya. Juga tidak ada satupun diantara anggota YPKP yang Pro dengan ajaran Komunis/PKI, karena tidak ada doktrin yang diberikan olehYPKP kepada anggota-anggotanya.

\section{a. Interaksi YPKP dengan Kesbangpol}

Interaksi YPKP dengan pemerintah di kabupaten lebih kepada pemantauan dari Kesbangpol Kab. Pati. Memang pada dasarnya Kesbangpol lebih banyak mengetahui informasi dari Polri dan TNI. Mengingat saat ini Kesbangpol sudah tidak menangani atau berwenang melakukan Litsus (penelitian khusus) terhadap orang-orang atau kelompok yang dianggap/dicurigai membahayakan NKRI dan menyerang Pancasila (organisasi terlarang).

Maka apabila ditanyakan tentang aktivitas YPKP Kesbangpol sebagai bagian dari pemerintah juga memantau segala aktivitas YPKP juga berkoordinasi dengan berbagai pihak agar organisasi ini tidak melakukan tindakan anarkis. Sdr Cipto juga sangat kooperatif dengan penulis dan memberikan banyak informasi.

YPKP ini semakin sering muncul di Jawa Tengah khususnya saat adanya kemunculan majalah lentera di Kab. Salatiga dan dari maraknya penyebaran atribut palu arit sehingga aktivitas dari YPKP ini perlu terus di pantau oleh pemerintah maupun aparat. Kesbangpol juga kerap di kunjungi oleh Ketua YPKP Kab. Pati namun hanya sekedar berkoordinasi biasa karena memang ketua YPKP Kab. Pati juga sebagai aparat pemerintah. Namun apabila berbicara mengenai kegiatan YPKP, maka apabila ada perkumpulan dan aktivitas lainnya maka harus meminta ijin kepada pihak kepolisian. 


\section{b. Interaksi YPKP dengan LPSK}

Selain adanya Interaksi dengan pemerintah, YPKP juga beriteraksi dengan LPSK (Lembaga Perlindungan Saksi dan Korban) yang merupakan lembaga mandiri didirikan dan bertanggung jawab untuk menangani pemberian perlindungan dan bantuan pada Saksi dan Korban berdasarkan tugas dan kewenangan sebagaimana diatur dalam Undang-Undang. LPSK dibentuk berdasarkan UU No 13 Tahun 2006 tentang Perlindungan Saksi dan Korban.

Dalam kegiatan tersebut juga disampaikan oleh LPSK tentang aturan baru dalam penerimaan pengobatan bagi pasien LPSK, yaitu :

a) Anggota YPKP 65 yang mendapatkan pengobatan adalah korban langsung kejadian pada th. 1965 dan bagi istri yang mendapat pengobatan adalah istri pertama.

b) Usia diatas 60 tahun.

c) Pemberian santunan kematian sebesar 2 juta rupiah

d) Pengobatan yang semula bersifat rujukan dari LPSK ke rumah sakit yang telah ditentukan

e) Jumlah pengobatan tidak dibatasi, namun uang transport pengobtan sebulan hanya dua kali, masing-masing sebesar Rp. 180.000,-

f) Anggota YPKP 65 Di kab. Pati yang datang mengambil uang transport pengobatan sebanyak 45 ( empat puluh lima) orang.

Memang pada kenyataanya sangat sulit dan panjang tahapan yang harus dilalui bila ingin memperoleh bantuan dari LPSK. Maka YPKP mengupayakan untuk terus meningkatkan jumlah anggota agar menerima bantuan dari LPSK.

Kegiatan yang pernah dilakukan YPKP Kab. Pati terkait hubungan dengan LPSK yaitu kegiatan yang masih berlangsung rutin setiap bulannya, pengobatan gratis yang difasilitasi oleh LPSK (Lembaga Perlindungan saksi Korban) di rumah Sdr. SUPARDI als BEDONG, dengan petugas medis dari RS. KSH Pati setiap sebulan sekali.

Semua korban di data dan hanya sebagian yang berhasil lolos menerima bantuan. Tiap bulannya para korban yg lolos tersebut berkumpul di rumah Sdr. Supardi, hanya disuguhi air putih dan camilan seadanya, lalu mereka duduk diatas alas yang terbuat dari tikar jerami. Tak lama orang-orang dari LPSK datang dan mendata serta memberikan kertas yang harus diisi oleh anggota YPKP yang ingin mendaftar sebagai penerima bantuan dari LPSK. Apabila yang sudah menerima biasanya langsung ke rumah sakit untuk menerima pengobatan gratis.

Kondisi kesehatan para anggota YPKP ini pun cukup memprihatinkan, usia yang sudah tidak lagi muda juga ada yang terkena gangguan mental karena merasa sangat tertekan dan teraniaya saat di tahan di pulau buru, bahkan ada pula yang telinganya hampir putus bekas penyiksaan saat di tahan di pulau buru. Mereka yang sudah tua ini berkumpul dan kerap menceritakan apa yang mereka alami selama menjadi korban, ditahan tanpa diadili dengan jelas putusan hukum nya, juga mereka tidak merasa terlibat namun tiba-tiba ditangkap. Hampir sebagian besar dari anggota YPKP 65 ini dalam kondisi ekonomi yang memprihatinkan. Banyak yang berprofesi sebagai buruh tani, tukang pijat akupungtur dan ada pula yang hanya tinggal di rumah di urus oleh anak cucunya.

\section{Dinamika}

Dinamika yang terjadi dalam YPKP yaitu hubungan secara eksternal dengan organisasi yang sangat memiliki paham nasionalis dan sangat menentang segala sesuatu yang berbau komunis. Hal ini terlihat dari hasil penelitian sebagai beikut : 


\section{a. Laskar Merah Putih}

YPKP Kab. Pati juga memiliki dinamika dengan orgaisasi eksternal yang sangat menentang adanya organisasi yang terkait komunis. Hal ini menimbulkan konflik antar organisasi yang memiliki paham yang berbeda. Seperti misalnya dinamika yang bertentangan dengan YPKP yaitu organisasi Laskar Merah Putih.

Anggota Ormas Laskar Merah Putih pimpinan Sdr. M. Saim adalah salah satu organisasi kemasyarakatan berbasis massa yang didirikan tanggal 28 Desember 2000. Visi dari Ormas LMP adalah memerjuangkan dan mempertahankan Negara Kesatuan Republik Indonesia dari upaya-upaya tersistematis dan masyarakat yang madani, mandiri, terbuka egaliter berkesadaran hukum dan lingkungan, menguasai ilmu pengetahuan dan teknologi mendepankan watak dan moral yang beradab, memiliki etos kerja dan semangat kekaryaan serta disiplin yang tinggi dengan bingkai Bhinneka Tunggal Ika sebagai perekat dari Sabang sampai Merauke, sebagai manusia Indonesia yang siap secara mental dan spirituil untuk memberikan dharma bhaktinya bagi Bangsa dan Negara sebagai alat sosial kontrol dalam pengabdian kepada masyarakat bangsa dan negara, maka dipandang perlu mendirikan yayasan-yayasan, lembaga-lembaga, forum-forum dan gerakan yang merupakan keluarga besar Laskar Merah Putih sehingga dapat memudahkan pelaksanaan tugas sesuai dengan bidangnya masing-masing.

Dalam gerakannya Ormas LMP turut mendukung dalam pemberantasan aliran radikalis atau terorisme yang bertolak belakang dengan islam sebenarnya. Sebab aliran radikalisme kini sudah menimbulkan keresahan pada masyarakat dan paham-paham tersebut mengancam terhadap keberagaman bangsa Indonesia dan NKRI. Kegiatan yang dilaksanakan LMP berupa kegiatan insidental seperti turut serta membantu korban bencana alam dan kegiatan rutin seperti arisan keliling di rumah anggota LMP. Kegiatan sosial yang pernah dilaksanakan seperti memfasilitasi anak jalanan agar tidak menjadi pelaku kriminal yang akan meminimalisir kejahatan dijalanan;

Paham dari LMP ini bahwa semua paham yang bertentangan dengan undangundang dasar RI harus diperangi. Jangan sampai persatuan bangsa Indonesia dirusak oleh paham-paham radikalisme dan anti pancasila. Untuk itu, pihaknya juga ikut mengecam adanya aksi bom bunuh diri dan menolak segala bentuk kekerasan serta aksi terorisme. Karena kebinekaan terancam dengan terorisme. Waspadai terhadap pahampaham baru dan munculnya paham radikalisme harus menjadi musuh bersama, termasuk juga aliran-aliran sesat.

Ormas LMP menyatakan siap membantu sepenuhnya dan mendukung program pemerintah dalam memerangi gerakan radikalisme dan anti pancasila yang muncul di Indonesia, sebab menurutnya aliran radikalisme tersebut mengancam Negara Kesatuan Republik Indonesia (NKRI), yang semestinya NKRI itu sudah menjadi harga mati.

Anggota unit Intelkam Polwes Wedarijaksa dalam hal ini penulis mewawancarai Kanit Intel Polsek Wedarijaksa Sdr. Pitoyo menyampaikan bahwa telah melakukan penggalangan pada Ormas Laskar Merah Putih Kab. Pati yang diketuai Sdr. M. Saim beserta anggotanya. Penggalangan terhadap kelompok LMP dilakukan dengan maksud agar dapat turut serta meredam penyebaran faham-faham anti Pancasila seperti faham Komunis maupun faham lain yang bertentangan.

Hasil penggalangan terhadap Ormas YPKP $65 \mathrm{Kab}$. Pati bahwa kelompok tersebut menyatakan bersedia bekerjasama dengan pemerintah khususnya Kepolisian dalam memerangi penyebaran paham Komunis dan anti pancasila. YPKP melalui ketuanya Sdr. Handoyo berani menjamin anggotanya tidak akan pernah memakai atribut maupun logo-logo yang bernuasa PKI bahkan sampai berencana membangkitkan PKI di Indonesia. 
Penulis ikut melaksanakan pertemuan terhadap Ormas Laskar Merah Putih yang berkoordinasi dengan kepolisian di Rumah makan Soto Semarang Kab. Pati. Penulis melihat bahwa laskar merah putih berkoordinasi dengan pihak kepolisian dan menjalin integrasi yang baik sehingga apabila ada tindakan tindakan yang sekiranya melawan dan menentang pancasila serta bersifat radikal, maka LMP akan bekerjasama dengan kepolisian untuk menangani hal tersebut.

Guna mencegah berkembangnya faham komunis khususnya dikalangan mantan eks. Tapol G30S dan keluarganya maka perlu dilakukan langkah-langkah antisipasi di seluruh wilayah Jateng, antara lain dengan meningkatkan koordinasi dengan aparat terkait guna menyamakan persepsi dalam pemahaman dan penanganannya, meningkatkan deteksi dini dan deteksi aksi terhadap keberadaan anggota YPKP di wilayah, mendatakan dan melaporkan setiap kegiatan YPKP di wilayah masing-masing, juga melaksanakan penggalangan baik perorangan maupun kelompok sehingga dalam setiap kegiatannya tidak menimbulkan permasalahan baru.

\section{b. FPI (Front Pembela Islam)}

Dinamika yang terjadi juga antara YPKP 65 dengan FPI. Kejadian ini terjadi saat acara Simposium Tragedi 1965 tanggal 18-19 Mei 2016 di Jakarta yang intinya pemerintahan Jokowi ingin mendengar keinginan dari para korban, karena pelaku Tragedi1965 tidak mungkin dituntut secara hukum dengan pertimbangan kasus dengan hukuman 3 tahun masa kedaluwarsa 12 tahun, dan kasus dengan putusan hukuman mati masa kedaluwarsa 18 tahun, jadi jalan satu-satunya adalah mencari solusi secara non yudisial. Stigma yang terbangun saat ini adalah pihak korban terlalu didoktrin seolah-olah seperti sampah negara.

YPKP ini juga menampung para korban maupun keluarga korban 1965 yang tergabung dalam Ormas YPKP 65 (Yayasan Penelitian Korban Pembunuhan 1965/1966) G30S/PKI. Selanjutnya penulis mewawancarai Sdr. Supardi sebagai wakil ketua YPKP Kabupaten Pati. Beliau merupakan tokoh idealis dari YPKP 65 yang memerjuangkan hak - hak para korban peristiwa 1965 namun beliau menyadari bahwa tuntutannya tidak dapat dipenuhi oleh pemerintah dikarenakan bukti - bukti tidak kuat dan harus dilihat secara objektif.

\section{c. Dinamika dengan Tentara Nasional Indonesia (TNI)}

Sejumlah eks tahanan politik 1965 yang terlibat upaya pengungkapan kuburan masal 1965 mengaku diteror dan diintimidasi oleh aparat keamanan di wilayah asal mereka.Sebagian mengklaim mendapat teror dan intimidasi antara lain melalui telepon dari petugas ketika berusaha menemui Menkopolhukam di kantornya.

Pernyataan ini pun dirasakan di wilayah yaitu di YPKP 65 Kab. Pati yang merasa di intimidasi oleh TNI. Maka YPKP cenderung lebih kooperatif dengan mahasiswa.

Karena itulah, menurut Ketua YPKP '65 Bejo Untung, mereka kemudian meminta jaminan keamanan kepada Menkopolhukam yang meminta jaminan dari bapak Menkopolhukkam agar YPKP 65 dijamin keamanannya dalam rangka untuk menunjukkan kuburan masal. Mereka juga meminta jaminan pemerintah agar keberadaan kuburan masal tersebut diamankan dari kemungkinan dirusak atau dihilangkan oleh pihak lain. Luhut Pandjaitan yang saat itu menjabat sebagai Menkopolhukam berjanji akan menindaklanjuti permintaan mereka dengan menelpon aparat TNI-AD di daerah. Usai pertemuan dengan pimpinan YPKP '65, Luhut Pandjaitan yang saat itu sebagai Menkopolhukam tidak memberikan keterangan kepada pers tentang hasil pertemuan 122 titik kuburan masal 1965. 
Pernyataan Presiden mengenai pengungkapan kuburan masal itu muncul menyusul berakhirnya Simposium tragedi 1965 yang menyimpulkan adanya keterlibatan negara dalam peristiwa kekerasan terhadap orang-orang yang dituduh simpatisan PKI.

\section{PENUTUP}

Berdasarkan penelitian yang dilakukan di lapangan dan analisis yang dilakukan oleh penulis, maka simpulan dari penelitian ini adalah sebagaimana berikut:

Peran YPKP Kab Pati dalam Memperjuangkan Hak Korban G30S diataranya, YPKP 65 Kabupaten Pati melakukan konsolidasi secara internal dan eksternal dengan mengadakan rapat rutinan agar komunikasi yang terjalin sesama anggota . lancar, begitu pun komunikasi terhadap organisasi sejenis lainnya seperti LPSK serta stakdeholder yang selama ini membantu. YPKP 65 Kabupaten Pati menggunakan media komunikasi / saluran komunikasi yang bersifat elektronik untuk mendapatkan informasi yang berkaitan dengan tujuan organisasi. YPKP 65 Kabupaten Pati juga menggunakan sarana lain seperti media cetak Internet dan lain sebagainya. YPKP 65 Kabupaten Pati melakukan interaksi dengan organisasi lainnya, yaitu menggalang keterpaduan kerja baik intern maupun ekstern dengan lembaga atau pihak lain yang potensial untuk meningkatkan daya guna dan hasil guna proses komunikasi dengan meminta bantuan dari stakeholder seperti LPH YAPHI, LPSK, dan lain sebagainya. Kerjasama ini pun memberikan kontribusi bagi anggota YPKP dengan adanya penerimaan bantuan kesehatan yang diterima oleh anngota YPKP.

Mengacu kepada hambatan yang dialami YPKP 65 Kabupaten Pati dalam memperjuangkan Hak Korban G30S yaitu merekrut anggota YPKP 65 Kabupaten Pati yang memiliki SDM yang lebih baik, baik dari keluarga maupun dari orang-orang yang memiliki pandangan terbuka terhadap keberadaan dan perjuangan YPKP Kabupaten Pati. Menggunakan sarana dan prasarana termasuk media/saluran komunikasi yang memadai dan lebih canggih seperti internet dan lain sebagainya.Menghidupkan ruang diskusi dengan mengundang pakar-pakar HAM,nhukum, sosiologi dan LSM yang menangani masalah terkait. Lebih aktif dalam bersinergi dengan stakeholder serta menggunakan sistem administrasi yang baik, sehingga informasi dicatat dengan sistematis.

\section{DAFTAR REFERENSI}

Adian, Donny Gahral. 2010. Demokrasi Substansial : Risalah Kebangkrutan Liberalisme. Depok: Koekoesan .

A. Rahman H.I. 2011. Sistem Politik Indonesia. Jakarta : PT Raja Grafindo Persada

Arif Budi Prasetyo. 2009. Kasus Pembunuhan Munir. Jakarta : PT. Gramedia Pustaka Utama.

Biddle, B.J., \& Thomas, E. J. (1996). Role theory: Concept and research. New York: Willey. Boeree, George. Personality Theories: Melacak Kepribadian Anda Bersama

Psikolog Dunia,(Jogjakarta: Prismasophie, 2010).

Budiarjo, Miriam. 2008. Dasar-Dasar Ilmu Politik. Jakarta: PT Gramedia Pustaka Utama. Creswell, John W. 2014. Research design pendekatan kualitatif, kuantitatif, dan mixed.

Yogyakarta : Pustaka Pelajar

Harsojo. 1977. Pengantar Antropologi. Bandung : Bina Cipta

Horton, B. Paul dan Hunt, L. Chester. 1984. Sosiologi Jilid I, Jakarta: Erlangga. 
Huntington, Samuel P. 1990. Partisipasi Politik di Negara Berkembang. Jakarta: Rineka Cipta

Idrus, Muhammad. 2007. Metode Penelitian Ilmu Sosial. Jakarta : UII Press

Moleong, Lexy J. 2007. Metodologi Penelitian Kualitatif. Bandung: Remaja Rosdakarya. 